\title{
Clinical entity
}

INSERM

\section{Source}

INSERM. (1999). Orphanet: an online rare disease and orphan drug data base. Clinical entity. ORPHA:COO1

A set of phenotypic abnormalities. 